\title{
The microbiome in bronchiectasis
}

\author{
Hollian Richardson, Alison J. Dicker, Heather Barclay and James D. Chalmers
}

Affiliation: Scottish Centre for Respiratory Research, University of Dundee, Dundee, UK.

Correspondence: James D. Chalmers, Scottish Centre for Respiratory Research, University of Dundee, Ninewells Hospital and Medical School, Dundee, DD1 9SY, UK. E-mail: j.chalmers@dundee.ac.uk

@ERSpublications

Studies of the microbiome in bronchiectasis demonstrate an association between Pseudomonas, Haemophilus and other genera with exacerbations. Lower microbiome diversity correlates with greater disease severity. Larger studies are needed. http://bit.ly/2xwROOR

Cite this article as: Richardson $\mathrm{H}$, Dicker AJ, Barclay $\mathrm{H}$, et al. The microbiome in bronchiectasis. Eur Respir Rev 2019; 28: 190048 [https://doi.org/10.1183/16000617.0048-2019].

ABSTRACT Bronchiectasis is increasing in prevalence worldwide, yet current treatments available are limited to those alleviating symptoms and reducing exacerbations. The pathogenesis of the disease and the inflammatory, infective and molecular drivers of disease progression are not fully understood, making the development of novel treatments challenging. Understanding the role bacteria play in disease progression has been enhanced by the use of next-generation sequencing techniques such as 16S rRNA sequencing. The microbiome has not been extensively studied in bronchiectasis, but existing data show lung bacterial communities dominated by Pseudomonas, Haemophilus and Streptococcus, while exhibiting intraindividual stability and large interindividual variability. Pseudomonas- and Haemophilus-dominated microbiomes have been shown to be linked to severe disease and frequent exacerbations. Studies completed to date are limited in size and do not fully represent all clinically observed disease subtypes. Further research is required to understand the microbiomes role in bronchiectasis disease progression. This review discusses recent developments and future perspectives on the lung microbiome in bronchiectasis.

\section{Introduction}

Bronchiectasis is a common chronic lung disease with heterogeneous clinical features and outcomes $[1,2]$. The prevalence of bronchiectasis in Europe and North America ranges from 67 to 566 per 100000 inhabitants, and is as high as a 1200 per 100000 in China, making it a serious and growing economic health burden [3-5].

The cause of disease progression is hypothesised to be the result of a complex interaction between chronic infection, inflammation and impaired mucociliary clearance, which leads to structural changes in the lungs, allowing further infections to develop [6-9]. Each of these individual components interacts with the others, allowing the disease to progress.

Disease-associated exacerbations have a major effect on patient healthcare costs as well as quality of life due to increased lung damage and mortality risk [10-13]. Microorganisms such as Pseudomonas aeruginosa and, to a lesser extent, other Gram-negative and Gram-positive microorganisms identified in culture, have been linked to disease progression, poor clinical outcomes in bronchiectasis and driving airway neutrophil-mediated inflammation [14-19]. For this reason, long-term antibiotic therapy is one of the mainstays of treatment for the management of bronchiectasis with frequent exacerbations [10, 13, 20, 21]. The development of accessible molecular methods for studying lung microbial communities is changing our understanding of airway microbiology [22]. In turn, this is affecting our understanding of the contribution of infection to the pathophysiology of bronchiectasis. The microbiome has the potential to provide valuable

Provenance: Commissioned article, peer reviewed.

Received: 28 April 2019 | Accepted after revision: 01 July 2019

Copyright CERS 2019. This article is open access and distributed under the terms of the Creative Commons Attribution Non-Commercial Licence 4.0. 
information regarding disease phenotype/endotype, treatment responses and targets for future therapy [23-25]. In this review, we discuss the potential role of the microbiome in bronchiectasis.

\section{Healthy lung microbiome}

The microbiome is defined as the combined genetic material of all microorganisms in an environment [26]. This is distinct from the microbiota, which is defined as the ecological community of commensal, symbiotic and pathogenic microorganisms found in a specific niche. In practice, these terms are often used interchangeably. Central to the field of microbiome research is an understanding that the human body is host to a vast array of different microorganisms that interact with the host and each other to produce important effects of health and disease [27, 28]. Traditionally, clinical practice has used culture to investigate bacteria in the lungs, but this selects for growth of known, predominantly aerobic, respiratory pathogens [29]. Molecular-based methods offer an alternative to culture and include 16S ribosomal (r) RNA sequencing and metagenomic sequencing [29]. These methods aim to capture genetic information from all bacteria, or in the case of metagenomics, all DNA sequences, present in a sample. The rapid development of this field has required clinical researchers to rapidly adopt a new language for describing lung microbial communities and their impact on disease. Current general microbiome terminology is described in table 1. Common phyla identified by $16 \mathrm{~S}$ rRNA sequencing in the healthy lung include Proteobacteria, Firmicutes and Bacteroidetes, while at the genus level Streptococcus, Prevotella and Veillonella predominate, with lesser contributions from Haemophilus and Neisseria [29-31]. The healthy lung microbiome is believed to be transient and depends on three factors, as follows. 1) Microbes moving into the airways from inhalation, microaspiration and direct mucosal dispersion; 2) the speed at which the mucocilliary system and innate immune system remove microbes; and 3) whether conditions in certain regions of the lung are able to favour microbial growth [32]. Lung disease alters the structure of the lung and changes regional growth conditions. The modifiers of the lung microbiome are illustrated in figure 1 . In bronchiectasis the airways become widened, leading to a failure of mucociliary clearance allowing bacterial adherence, increased bacterial loads and the development of chronic infection [8].

\section{Bronchiectasis microbiome versus culture}

The field of microbiome research in bronchiectasis is less advanced than the field of other respiratory diseases such as cystic fibrosis and chronic obstructive pulmonary disease (COPD), with fewer published studies [33-36]. Nevertheless, evidence to date suggests remarkable consistency in findings across supposedly distinct disease entities [37-40]. The first group of published bronchiectasis microbiome studies have supported the findings of culture-based studies, identifying genera associated with infection such as Haemophilus, Streptococcus and Pseudomonas, while also providing evidence of bacterial pathogens in culture-negative patients [41-43]. The microbiology of bronchiectasis and a representative microbiome profile for the bronchiectasis population (hypothetical data based on published work) are shown in figure 2 [44-46]. Overall, bronchiectasis microbiome studies support the findings reported by culture in terms of dominant organisms. Microbiome studies have shown the bronchiectasis microbiome is

\section{TABLE 1 Commonly used terminology in microbiome studies}

\begin{tabular}{|c|c|}
\hline Microbiota & includes bacteria, fungi and viruses \\
\hline Microbiome & $\begin{array}{l}\text { tic information and inferred physiochemical properties of the gene products of the microbiota. In most articles the } \\
\text { used to mean the taxonomic classification of bacteria present in a sample and is used as such in this review }\end{array}$ \\
\hline Bacteriome & $\begin{array}{l}\text { he genetic information and inferred physiochemical properties of the gene products of the bacteria present in a specific } \\
\text { location }\end{array}$ \\
\hline Mycol & he genetic information and inferred physiochemical properties of the gene products of the fungi present in a specific loca \\
\hline Viron & \\
\hline Metagenomics & $\begin{array}{l}\text { ost and microbe origin, which is analysed, } \\
5\end{array}$ \\
\hline gene & molecular studies owing to its extremely slow \\
\hline OTUs & $\begin{array}{l}\text { Clusters of similar 16S rRNA gene sequences. Each OTU represents a taxonomic unit of a bacteria family or genus } \\
\text { depending on the sequence similarity threshold. Identification to the species level is not usually possible }\end{array}$ \\
\hline$\alpha$-diversity & $\begin{array}{l}\alpha \text {-diversity is a measure of how diverse a sample is based on how many species there are (richness) and how abundant each } \\
\text { species is (evenness) within that sample }\end{array}$ \\
\hline$\beta$-dive & $\begin{array}{l}\text {-diversity is used to show how different samples are from each other, based on differences in bacterial presence, } \\
\text { abundance or a phylogenetic tree }\end{array}$ \\
\hline
\end{tabular}

rRNA: ribosomal RNA; OTUs: operational taxonomic units. 


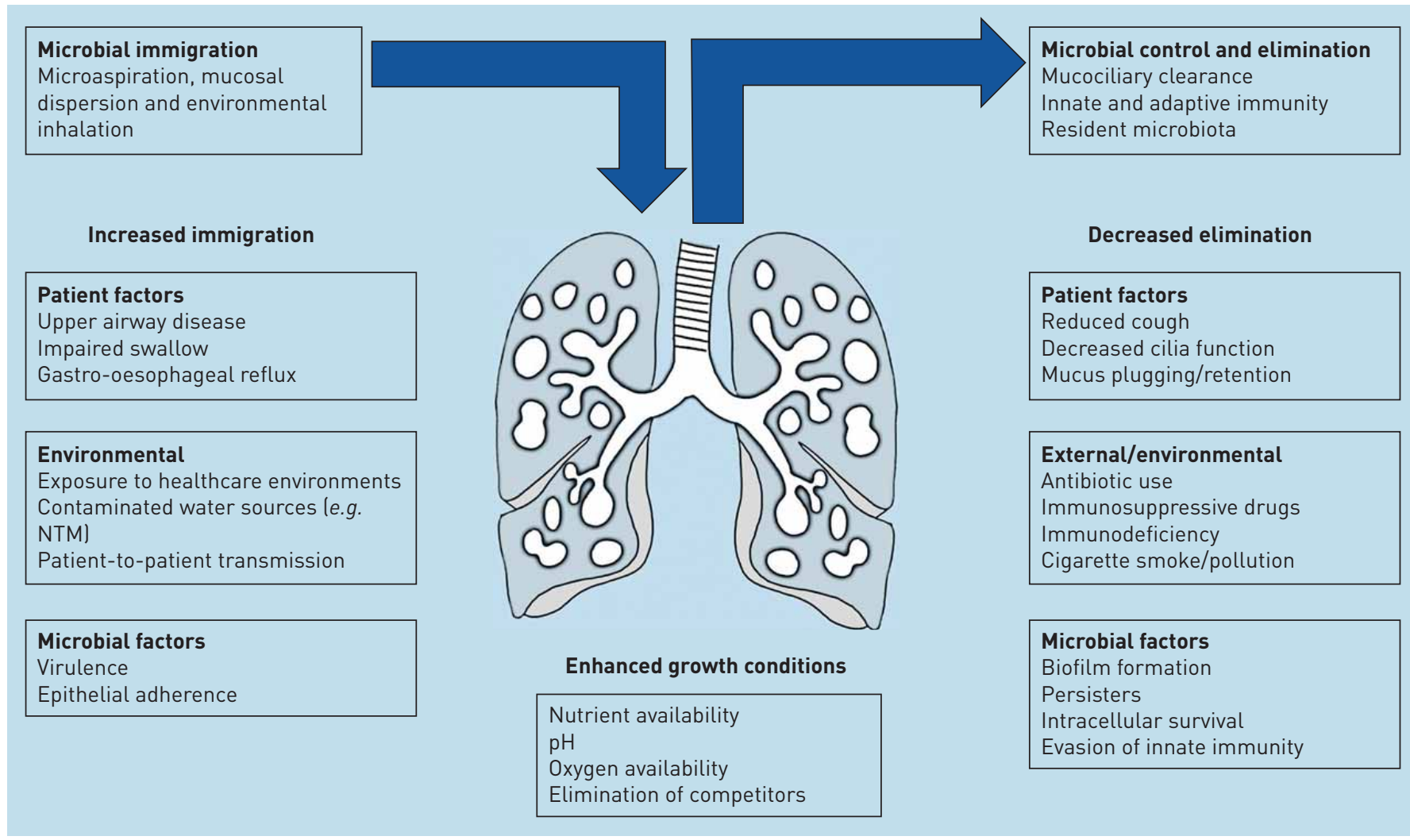

FIGURE 1 Illustration of the factors modifying the healthy and diseased lung microbiome. The arrows illustrate the immigration of bacteria to the lungs and the balanced removal of bacteria by mucociliary clearance and immune clearance. Multiple factors have been described that increase immigration of bacteria and decrease clearance, leading to dysbiosis. The list is not intended to be comprehensive. NTM: nontuberculous mycobacteria.

complex, contains multiple bacterial genera and is highly individual $[46,47]$. A recent longitudinal study by Woo et al. [48] followed 29 bronchiectasis patients for up to 16 years and demonstrated remarkable stability of the microbiome over many years of follow-up. The microbiomes of Pseudomonas- and Haemophilus-dominated patients were widely divergent and patients maintained similar profiles over time despite antibiotic treatments [48]. This is consistent with what has been seen with culture, where chronic infection with $P$. aeruginosa or $H$. influenzae often persists over many years regardless of therapy [49]. Few studies have examined the microbiome during exacerbations, but these are reviewed later.

A minority of studies have used quantitative (q) real-time PCR to determine bacterial load, as 16S rRNA sequencing cannot quantify the bacteria present. The reported bacterial load in bronchiectasis patients ranged from $10^{4}$ to $10^{10} \mathrm{CFU} \cdot \mathrm{mL}^{-1}$ when total viable counts and $\mathrm{qPCR}$ have been performed $[47,50]$.

Does the microbiome play a role in exacerbations and affect disease severity?

Exacerbations in bronchiectasis can be caused by a range of bacteria, viruses and environmental factors; making it hard to determine the role of the microbiome in exacerbations [51]. It is known from culture studies that bacterial load is important in lung inflammation and treatment response [14, 52]. Microbiome changes during exacerbation are heterogeneous. In one study, some patients exhibited minimal changes, while in other patients marked changes in the relative abundance of different taxa occurred [47]. The overall conclusion by Cox et al. [47] was that there was no statistically significant increase in bacterial load during exacerbation compared to baseline, and there were no consistent changes in diversity or other microbiome parameters during exacerbation. This does not mean that the microbiome is not involved in exacerbations of bronchiectasis patients, but suggests that there are some, as yet identified, subtypes of exacerbations associated with diverse changes [47]. Furthermore, there was no significant difference in bacterial load between baseline, exacerbation, treatment and recovery samples. In a pattern similar to what has been seen in cystic fibrosis, measures of $\alpha$ - and $\beta$-diversity across all patients in this study are associated with measures of clinical severity, including lung function [35, 47]. Several studies suggest that severe bronchiectasis is reduced with lower diversity of the microbiome measured by composite indices 
a)
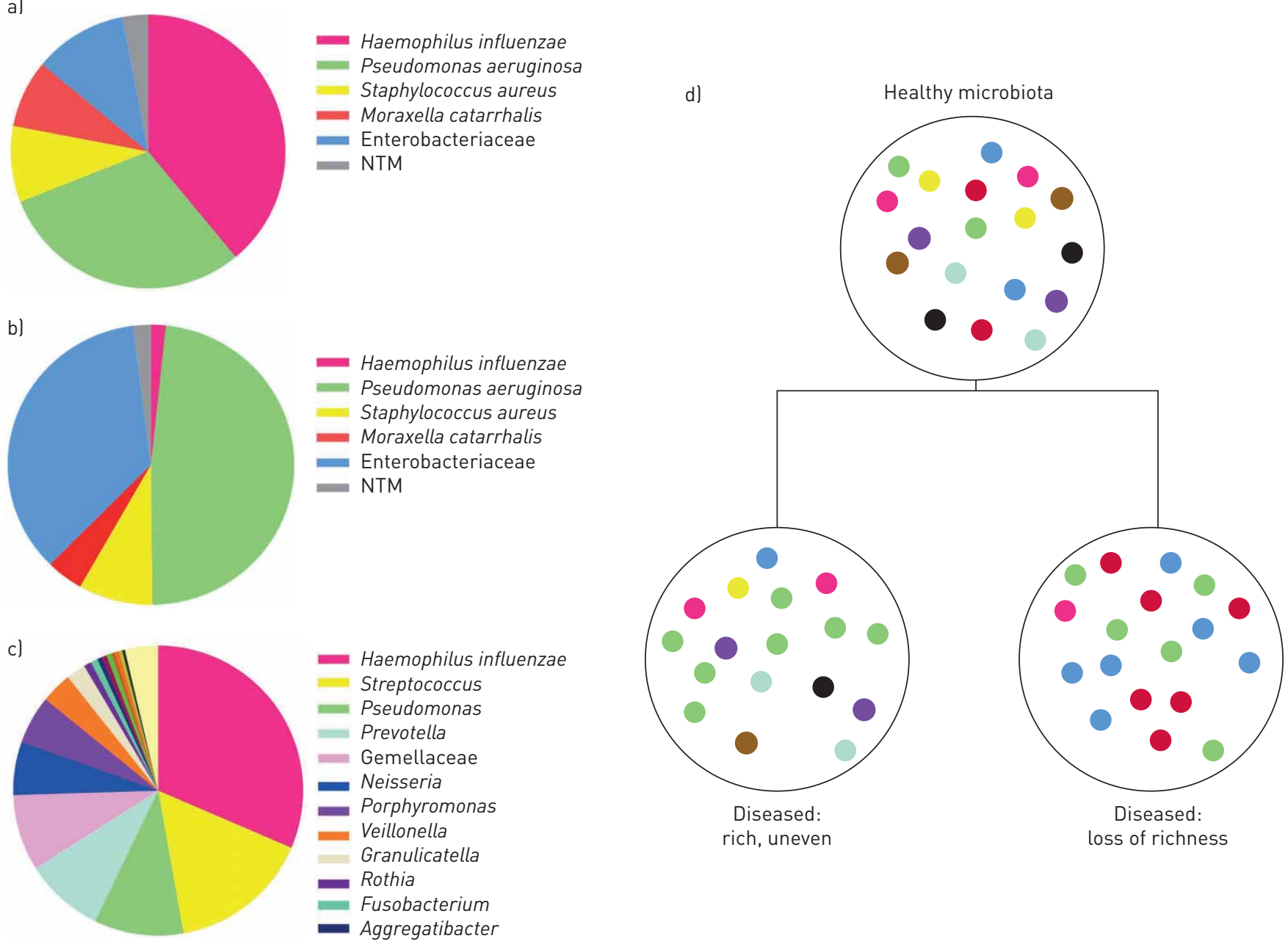

FIGURE 2 The microbiology of bronchiectasis. a) Culture-based microbiology results from a European cohort study [44]; b) culture-based microbiology results from the US Bronchiectasis Registry [43]; c) a representative microbiome profile for the bronchiectasis population (hypothetical data based on published work) [45] (low-abundance genera (<1\%) such as Leptotrichia are not shown); d) simplified concept of microbiota dysbiosis and loss of diversity in the bronchiectasis lung. NTM: nontuberculous mycobacteria.

such as the Shannon diversity index [42]. Woo et al. [48] demonstrated in their small study (n=29) that very low diversity values were associated with more rapid lung function decline.

In the BLESS (Bronchiectasis and Low-dose Erythromycin Study) study, low-dose erythromycin (400 mg, twice daily) was given to stable bronchiectasis patients for 48 weeks in a double-blind, placebo-controlled, randomised controlled trial [53]. The overall study demonstrated a significant reduction in exacerbations in the erythromycin-treated patients compared to placebo. When the microbiomes of the included patients were examined, it was shown that patients with a Haemophilus-dominated microbiome had fewer exacerbations, while patients with a Pseudomonas- or Veillonella-dominated microbiome profile had an increased frequency of exacerbations overall (in both the active agent- and placebo-treated patients) [54]. Patients with $P$. aeruginosa infections are known to have poorer clinical outcomes, including more frequent exacerbations, decline in lung function, higher requirement for antibiotic therapy and greater sputum production [12, 55-58]. In the BLESS study, Pseudomonas- or Haemophilus-dominated microbiomes were associated with significantly reduced lung function compared to other microbiome profiles (forced expiratory volume in $1 \mathrm{~s} 56.8 \%, 69.9 \%$ and $73.1 \%$, respectively) [54].

Using the BLESS cohort, the microbiome was compared to measures of inflammation including sputum interleukin (IL)-1 $\beta$, IL-8, matrix metalloproteinases (MMPs) and serum C-reactive protein (CRP) [50]. Genus richness was negatively associated with sputum IL-1 $\beta$ and IL-8, while Pseudomonas- or Haemophilus-dominated microbiomes were associated with increased levels of serum CRP, sputum IL- $1 \beta$ and IL-8 [50,54]. Stratifying patients based on dominant microbiome showed that $H$. influenza-dominated microbiomes had significantly higher levels of MMP2 $(\mathrm{p}<0.01)$ and MMP8 $(\mathrm{p}<0.03)$ compared to those 
with a Pseudomonas-dominated microbiome [50]. It is important to consider that this dataset (86 patients) is relatively small, with modest numbers of Haemophilus- (31 patients) or Pseudomonas- (22 patients) dominated microbiomes. Larger studies are required to confirm these findings.

\section{Antibiotics and the bronchiectasis microbiome}

The findings from the BLESS study are cross-sectional and do not discuss the effects of the antibiotic treatment itself. In a post hoc analysis of the BLESS study, a significant change in the microbiome was observed in the erythromycin group compared to placebo with a significant increase in microbiome richness [46]. The response was different depending on the infecting organism at baseline. Erythromycin did not result in significant changes in microbiome composition evaluated by the Bray-Curtis dissimilarity index in patients with a Pseudomonas-dominated microbiome, but significantly reduced the rate of pulmonary exacerbations compared to placebo in this group [42]. Erythromycin reduced the relative abundance of Haemophilus in patients with non-Pseudomonas-dominated microbiomes and promoted displacement with more macrolide-tolerant pathogens, but did not significantly reduce the rate of pulmonary exacerbations. Furthermore, an increased relative abundance of Pseudomonas was observed in these patients [42]. The clinical significance of this finding is uncertain, as macrolide therapy is highly beneficial in the treatment of bronchiectasis, but these data raise a concern that it may promote infection with Pseudomonas, which has a worse outcome over the longer term [59]. The impact of inhaled antibiotics on the microbiome has not been investigated. Ideally, the impact on the lung microbiome by all the commonly used antibiotics to treat respiratory infections in bronchiectasis needs to be investigated [60].

\section{The role of fungi, viruses and nontuberculous mycobacteria}

The role of fungi, viruses and nontuberculous mycobacteria (NTMs) in bronchiectasis are less well defined, but are likely to be significant in bronchiectasis [28, 61]. The CAMEB (Cohort of Asian and Matched European Bronchiectasis) study was the first to investigate the lung mycobiome in a cohort of 238 Asian and matched European bronchiectasis patients. Common genera observed in the bronchiectasis mycobiome were Aspergillus, Cryptococcus and Clavispora [62]. Geographical variation was observed, with two different Aspergillus species detected using qPCR. Aspergillus fumigatus was detected as the predominant species in patients from Singapore/Kuala Lumpur and Aspergillus terreus was predominant in patients from Dundee. Further investigation of the lung mycobiome needs to be performed.

Several viruses, including influenza $A$ and $B$, adenovirus, parainfluenza, rhinovirus and human T-lymphotropic virus-1 have been identified in bronchiectasis patients [63-66]. Mitchell et al. [67] conducted two studies using PCR, including 47 and 27 patients, and identified viruses in 39\% and 59\% of bronchiectasis patients, respectively, during stable state. This suggests a remarkably high frequency of viruses even during stable disease. However, extensive virome studies have not been performed. Further studies need to investigate whether viruses are a cause or consequence of exacerbations. It has been suggested that viruses play a role in bronchiectasis exacerbations even when bacterial load and diversity are stable [63].

The role of NTMs in the bronchiectasis microbiome is less understood. Common NTMs reported include members of the Mycobacterium avium complex and Mycobacterium abscessus complex [68-70]. It is possible that NTMs act as a trigger for bronchiectasis as hypothesised with Mycobacterium avium subspecies paratuberculosis and Crohn's disease [71]. The role of fungi, NTM and viruses are currently less studied, in part due to limitations of the methods used. These organisms, particularly fungi and Mycobacteria, present difficulties related to DNA extraction, as well as the lack of agreement on appropriate methods for sequencing and databases to identify micro-organisms. The widely used $16 \mathrm{~S}$ rRNA sequencing methods used for microbiome studies do not identify Mycobacteria accurately [72]. Sulaiman et al. [72] studied a cohort of patients with NTM infection using 16S rRNA sequencing, and despite these patients being culture-positive for NTM, few mycobacteria were identified by sequencing. There was an association between oral commensals and inflammatory responses, suggesting a modulating effect of other microbiota in NTM lung disease.

\section{What is still missing?}

To date, microbiome data have not led to changes in clinical practice, but it is important to investigate associations between the microbiome and clinical presentation to help guide treatment. Previous bronchiectasis microbiome studies have been limited by the number of patients tested $(<150$ patients) and the duration of patient follow-up ( $<1$ year). Future microbiome studies need to have an extended follow-up period and include larger numbers of patients to capture the disease heterogeneity during stability and at exacerbation. Ideally, methodology in future microbiome studies needs to be standardised. Previous studies have shown this as there is variation in methodology from one study to the next, as shown in table 2. 


\begin{tabular}{|c|c|c|c|c|c|c|c|c|c|}
\hline $\begin{array}{l}\text { First author, } \\
\text { [ref.] }\end{array}$ & Year & $\begin{array}{l}\text { Sample } \\
\text { size } n\end{array}$ & $\begin{array}{l}\text { Sample } \\
\text { type }\end{array}$ & Patient characteristics & DNA extraction & $\begin{array}{l}16 S \\
\text { region }\end{array}$ & Sequencing method & Data analysis & Taxa found \\
\hline Byun [41] & 2017 & 14 & $\begin{array}{l}\text { Sputum, } \\
\text { BAL }\end{array}$ & Stable and exacerbated & $\begin{array}{c}\text { MG Blood Genomic DNA } \\
\text { Extraction SV kit (MGmed, Seoul, } \\
\text { Republic of Korea) }\end{array}$ & $\begin{array}{l}\mathrm{V} 2,4,8 \\
\mathrm{~V} 3,6- \\
7,9\end{array}$ & $\begin{array}{l}\text { Ion } 318 \text { v2 chip, lon } \\
\text { PGM Sequencing } 400 \\
\text { kit (Life Technologies, } \\
\text { Carlsbad, CA, USA) }\end{array}$ & $\begin{array}{l}\text { QIIME [37] and } \mathrm{R} \\
\text { packages }\end{array}$ & $\begin{array}{c}\text { Haemophilus, Pseudomonas, } \\
\text { Moraxella, Klebsiella, Prevotella and } \\
\text { Veillonella }\end{array}$ \\
\hline Cox [47] & 2017 & 76 & Sputum & $\begin{array}{c}\text { Stable and exacerbated } \\
\text { samples }\end{array}$ & $\begin{array}{c}\text { FastDNA Spin Kit for Soil (MP } \\
\text { Biomedicals, Santa Ana, CA, } \\
\text { USA) }\end{array}$ & V3-V5 & $\begin{array}{l}\text { Roche } 454 \mathrm{FLX} \\
\text { sequencer (Basel, } \\
\text { Switzerland) }\end{array}$ & $\begin{array}{l}\text { QIIME and } \mathrm{R} \\
\text { packages }\end{array}$ & $\begin{array}{c}\text { Haemophilus, Pseudomonas and } \\
\text { Staphylococcus }\end{array}$ \\
\hline Maughan [73] & 2012 & 31 & $\begin{array}{l}\text { Lung } \\
\text { tissue }\end{array}$ & $\begin{array}{l}\text { Surgical resection/lung } \\
\text { transplantation }\end{array}$ & $\begin{array}{c}\text { Direct PCR DNA Extraction } \\
\text { System (Viagen Biotech, Los } \\
\text { Angeles, CA, USA) }\end{array}$ & V1-V4 & $\begin{array}{l}\text { Applied Biosystems } \\
\text { (Foster City, CA, USA) } \\
\text { 3130XL sequencer }\end{array}$ & QIIME & $\begin{array}{c}\text { Pseudomonas, Stenotrophomonas, } \\
\text { Staphylococcus, Burkholderia and } \\
\text { Haemophilus }\end{array}$ \\
\hline Purcell [74] & 2014 & 70 & Sputum & $\begin{array}{c}20 \text { exacerbated, } 50 \\
\text { non-exacerbated }\end{array}$ & $\begin{array}{l}\text { MoBio Ultraclean Microbial DNA } \\
\text { isolation kit (MoBio, CA, USA) }\end{array}$ & V3 & Pyrosequencing & QIIME & $\begin{array}{l}\text { Pasteurellaceae, Streptococceae, } \\
\text { Pseudomonadaceae, } \\
\text { Prevotellaceae, Veillonellaceae and } \\
\text { Actinomycetaceae }\end{array}$ \\
\hline $\begin{array}{l}\text { Rogers } \\
\text { (BLESS) } \\
{[42]}\end{array}$ & 2013 & 41 & $\begin{array}{l}\text { Sputum, } \\
\text { BAL }\end{array}$ & $\begin{array}{l}\text { Clinically stable patients } \\
\text { with at least two infective } \\
\text { exacerbations in the } \\
\text { previous } 12 \text { months }\end{array}$ & $\begin{array}{l}\text { Laboratory-specific protocol } \\
\text { including a bead-beating step } \\
\text { and a phenol/chloroform } \\
\text { precipitation }\end{array}$ & $\mathrm{V} 1-\mathrm{V} 3$ & Pyrosequencing & $\begin{array}{l}\text { Custom C\# software } \\
\text { in MicrosoftH.NET } \\
\text { environment }\end{array}$ & $\begin{array}{c}\text { Pseudomonas, Haemophilus, } \\
\text { Streptococcus, Prevotella, Veillonella } \\
\text { and Neisseria }\end{array}$ \\
\hline $\begin{array}{l}\text { Rogers } \\
\text { (BLESS) } \\
{[54]}\end{array}$ & 2014 & 96 & Sputum & $\begin{array}{l}\text { Patients required to be } \\
\text { clinically stable, not } \\
\text { receiving systemic } \\
\text { corticosteroids and } \\
\text { macrolide-naive }\end{array}$ & $\begin{array}{l}\text { Laboratory-specific protocol } \\
\text { including a bead-beating step } \\
\text { and a phenol/chloroform } \\
\text { precipitation }\end{array}$ & V1-V3 & Pyrosequencing & $\begin{array}{l}\text { Custom C\# software } \\
\text { in MicrosoftH.NET } \\
\text { environment }\end{array}$ & $\begin{array}{l}\text { Haemophilus, Pseudomonas, } \\
\text { Veillonella and Streptococcus }\end{array}$ \\
\hline $\begin{array}{l}\text { Rogers } \\
\text { (BLESS) } \\
{[46]}\end{array}$ & 2014 & 96 & Sputum & As above & As above & V1-V3 & $\begin{array}{l}\text { Tag-encoded FLX } \\
\text { amplicon } \\
\text { pyrosequencing } \\
\text { (bTEFAP) }\end{array}$ & QIIME & N/A \\
\hline
\end{tabular}




\begin{tabular}{|c|c|c|c|c|c|c|c|c|c|}
\hline $\begin{array}{l}\text { First author, } \\
\text { [ref.] }\end{array}$ & Year & $\begin{array}{l}\text { Sample } \\
\text { size } n\end{array}$ & $\begin{array}{c}\text { Sample } \\
\text { type }\end{array}$ & Patient characteristics & DNA extraction & $\begin{array}{l}16 S \\
\text { region }\end{array}$ & Sequencing method & Data analysis & Taxa found \\
\hline $\begin{array}{l}\text { RogeRs } \\
\text { (BLESS) } \\
{[75]}\end{array}$ & 2015 & 60 & Sputum & Stable & As above & $\mathrm{V} 1-\mathrm{V} 3$ & Pyrosequencing & $\begin{array}{c}\text { PAST } \\
\text { (palaeontological } \\
\text { statistics) }\end{array}$ & $\begin{array}{c}\text { Patients stratified as Haemophilus- } \\
\text { or Pseudomonas-dominated } \\
\text { microbiomes }\end{array}$ \\
\hline $\begin{array}{l}\text { TAYLOR } \\
\text { (BLESS) } \\
{[50]}\end{array}$ & 2015 & 86 & Sputum & $\begin{array}{l}\text { Patients required to be } \\
\text { clinically stable, not } \\
\text { receiving systemic } \\
\text { corticosteroids and } \\
\text { macrolide naive }\end{array}$ & $\begin{array}{l}\text { Laboratory-specific protocol } \\
\text { including a bead-beating step } \\
\text { and a phenol/chloroform } \\
\text { precipitation }\end{array}$ & V1-V3 & $\begin{array}{l}\text { Bacterial tag- } \\
\text { endocoded FLX } \\
\text { amplicon } \\
\text { pyrosequencing }\end{array}$ & $\begin{array}{l}\text { Custom C\# software } \\
\text { in MicrosoftH.NET } \\
\text { environment }\end{array}$ & $\begin{array}{c}\text { Patients stratified as Haemophilus- } \\
\text { or Pseudomonas- or } \\
\text { other-dominated microbiomes }\end{array}$ \\
\hline TUNNEY [43] & 2013 & 29 & Sputum & $\begin{array}{l}\text { Stable and exacerbated } \\
\text { (pre- and post-antibiotics) }\end{array}$ & $\begin{array}{c}\text { FastDNA Spin Kit MP } \\
\text { Biomedicals, Santa Ana, CA, } \\
\text { USA) and OneStep TM PCR } \\
\text { Inhibitor Removal Kit (Zymo } \\
\text { Research, Irvine, CA, USA) }\end{array}$ & V1-V3 & Pyrosequencing & QIIME & $\begin{array}{l}\text { Haemophilus, Streptococcus, } \\
\text { Pseudomonas and Achromobacter }\end{array}$ \\
\hline $\begin{array}{l}\text { VAN DER GAST } \\
\text { (BLESS) } \\
\text { [76] }\end{array}$ & 2014 & $\begin{array}{c}19 \\
\text { children } \\
38 \text { adults }\end{array}$ & $\begin{array}{l}\text { Sputum, } \\
\text { BAL }\end{array}$ & Stable & $\begin{array}{l}\text { Laboratory-specific protocol } \\
\text { including a bead-beating step } \\
\text { and a phenol/chloroform } \\
\text { precipitation }\end{array}$ & V1-V3 & $\begin{array}{l}\text { Tag-encoded } \\
\text { FLX-titanium } \\
\text { pyrosequencing }\end{array}$ & Mothur, BLASTn & $\begin{array}{c}\text { Haemophilus, Pseudomonas, } \\
\text { Veillonella, Streptococcus and } \\
\text { Prevotella }\end{array}$ \\
\hline
\end{tabular}


It is unlikely that microbiome sequencing in its current form will ever make it into clinical practice; it is labour-intensive, time-consuming and requires specialised bioinformatics analysis. Third-generation sequencing techniques such as the MinION (Oxford Nanopore Technologies) and single-molecule real-time sequencing (PacBio) have the potential to be used in clinical practice. The MinION has been used previously for microbiological investigation of lower respiratory tract infections and in the INHALE study (UK) for rapidly identifying the cause of hospital-acquired and ventilator-associated pneumonia $[77,78]$. To be used in clinical practice any molecular method would need to be a "sample in/answer out" approach, something not currently possible with microbiome sequencing. Quantifying and identifying bacteria does not begin to address the complexity of host-microbiome interactions and, in addition, emerging techniques are starting to address bacterial metabolism, gene expression, resistance and host response. This is a rapidly developing field and these techniques will shortly be applied in bronchiectasis.

\section{Conclusion}

Compared to other lung diseases such as COPD and cystic fibrosis, the microbiome is far less understood in bronchiectasis; the majority of data have come from the BLESS trial $[53,79,80]$. In the next 5 years, the Bronchiectasis Research Involving Databases, Genomics and Endotyping (BRIDGE) study (NCT03791086) will sequence 1000 bronchiectasis patient samples from across Europe with the aim to determine molecular endotypes of bronchiectasis during stable disease. While this will provide valuable data, more research is needed to increase our understanding of the microbiome in heterogeneous populations of patients, both when stable and exacerbated and in response to different treatments. These data should be used to guide more personalised treatment approaches or to identify cohorts of patients more likely to respond to particular treatments within a clinical trial.

Conflict of interest: H. Richardson has nothing to disclose. A.J. Dicker has nothing to disclose. H. Barclay has nothing to disclose. J.D. Chalmers reports grants and personal fees from GlaxoSmithKline, Boehringer-Ingelheim, Pfizer, Bayer Healthcare, Grifols and Insmed, grants from AstraZeneca, and personal fees from Napp and Aradigm corporation, outside the submitted work.

\section{References}

1 Aliberti S, Polverino E, Chalmers JD, et al. The European Multicentre Bronchiectasis Audit and Research Collaboration (EMBARC) ERS Clinical Research Collaboration. Eur Respir J 2018; 52: 1802074.

2 Polverino E, Goeminne PC, McDonnell MJ, et al. European Respiratory Society guidelines for the management of adult bronchiectasis. Eur Respir J 2017; 50: 1700629.

3 Guan W-J, Gao Y-H, Yuan J-J, et al. Additional important research priorities for bronchiectasis in China. Eur Respir J 2017; 49: 1601747.

4 Lin J-L, Xu J-F, Qu J-M. Bronchiectasis in China. Ann Am Thorac Soc 2016; 13: 609-616.

5 Chandrasekaran R, Mac Aogáin M, Chalmers JD, et al. Geographic variation in the aetiology, epidemiology and microbiology of bronchiectasis. BMC Pulm Med 2018; 18: 83 .

6 Martinez-García MA. Pseudomonas aeruginosa infection and exacerbations in bronchiectasis: more questions than answers. Eur Respir J 2018; 51: 1702497.

7 Polverino E, Dimakou K, Hurst J, et al. The overlap between bronchiectasis and chronic airway diseases: state of the art and future directions. Eur Respir J 2018; 52: 1800328.

8 Flume PA, Chalmers JD, Olivier KN. Advances in bronchiectasis: endotyping, genetics, microbiome, and disease heterogeneity. Lancet 2018; 392: 880-890.

9 Frija-Masson J, Martin C, Regard L, et al. Bacteria-driven peribronchial lymphoid neogenesis in bronchiectasis and cystic fibrosis. Eur Respir J 2017; 49: 1601873.

10 Aksamit T, De Soyza A, Bandel T-J, et al. RESPIRE 2: a phase III placebo-controlled randomised trial of ciprofloxacin dry powder for inhalation in non-cystic fibrosis bronchiectasis. Eur Respir J 2018; 51 : 1702053.

11 Goeminne CP, Cox B, Finch S, et al. The impact of acute air pollution fluctuations on bronchiectasis pulmonary exacerbation: a case-crossover analysis. Eur Respir J 2018; 52: 1702557.

12 Chalmers JD, Aliberti S, Filonenko A, et al. Characterization of the "frequent exacerbator phenotype" in bronchiectasis. Am J Respir Crit Care Med 2018; 197: 1410-1420.

13 De Soyza A, Aksamit T, Bandel T-J, et al. RESPIRE 1: a phase III placebo-controlled randomised trial of ciprofloxacin dry powder for inhalation in non-cystic fibrosis bronchiectasis. Eur Respir J 2018; 51: 1702052.

14 Chalmers JD, Smith MP, McHugh BJ, et al. Short- and long-term antibiotic treatment reduces airway and systemic inflammation in non-cystic fibrosis bronchiectasis. Am J Respir Crit Care Med 2012; 186: 657-665.

15 Finch S, McDonnell MJ, Abo-Leyah H, et al. A comprehensive analysis of the impact of Pseudomonas aeruginosa colonization on prognosis in adult bronchiectasis. Ann Am Thorac Soc 2015; 12: 1602-1611.

16 Hilliam Y, Moore MP, Lamont IL, et al. Pseudomonas aeruginosa adaptation and diversification in the non-cystic fibrosis bronchiectasis lung. Eur Respir J 2017; 49: 1602108.

17 Spinou A, Siegert RJ, Guan W-J, et al. The development and validation of the Bronchiectasis Health Questionnaire. Eur Respir J 2017; 49: 1601532.

18 Pattison SH, Gibson DS, Johnston E, et al. Proteomic profile of cystic fibrosis sputum cells in adults chronically infected with Pseudomonas aeruginosa. Eur Respir J 2017; 50: 1601569.

19 Chalmers JD, Ringshausen FC, Harris B, et al. Cross-infection risk in patients with bronchiectasis: a position statement from the European Bronchiectasis Network (EMBARC), EMBARC/ELF patient advisory group and European Reference Network (ERN-Lung) Bronchiectasis Network. Eur Respir J 2018; 51: 1701937. 
Database Syst Rev 2016, 2016. CD012406.

456-463.

23 Chalmers JD, Chotirmall SH. Bronchiectasis: new therapies and new perspectives. Lancet Respir Med 2018; 6: $715-726$.

24 Agustí A, Bafadhel M, Beasley R, et al. Precision medicine in airway diseases: moving to clinical practice. Eur Respir J 2017; 50: 1701655.

25 Boaventura R, Sibila O, Agusti A, et al. Treatable traits in bronchiectasis. Eur Respir J 2018; 52: 1801269.

26 Watson RL, de Koff EM, Bogaert D. Characterising the respiratory microbiome. Eur Respir J 2019; 53: 1801711

27 Han MK, Zhou Y, Murray S, et al. Lung microbiome and disease progression in idiopathic pulmonary fibrosis: an analysis of the COMET study. Lancet Respir Med 2014; 2: 548-556.

28 Faner R, Sibila O, Agustí A, et al. The microbiome in respiratory medicine: current challenges and future perspectives. Eur Respir J 2017; 49: 1602086.

29 Dickson RP, Erb-Downward JR, Huffnagle GB. Homeostasis and its disruption in the lung microbiome. Am $J$ Physiol Lung Cell Mol Physiol 2015; 309: L1047-L1055.

30 Hilty M, Burke C, Pedro H, et al. Disordered microbial communities in asthmatic airways. PLoS One 2010; 5: e8578.

31 Dickson RP. The microbiome and critical illness. Lancet Respir Med 2016; 4: 59-72.

32 Dickson RP, Huffnagle GB. The lung microbiome: new principles for respiratory bacteriology in health and disease. PLoS Pathog 2015; 11: e1004923.

33 Breuer O, Caudri D, Akesson L, et al. The clinical significance of oropharyngeal cultures in young children with cystic fibrosis. Eur Respir J 2018; 51: 1800238.

34 Muhlebach MS, Hatch JE, Einarsson GG, et al. Anaerobic bacteria cultured from cystic fibrosis airways correlate to milder disease: a multisite study. Eur Respir J 2018; 52: 1800242.

35 Zemanick ET, Sagel SD, Harris JK. The airway microbiome in cystic fibrosis and implications for treatment. Curr Opin Pediatr 2011; 23: 319-324.

36 Zemanick ET, Wagner BD, Robertson CE, et al. Airway microbiota across age and disease spectrum in cystic fibrosis. Eur Respir J 2017; 50: 1700832.

37 Contoli M, Pauletti A, Rossi MR, et al. Long-term effects of inhaled corticosteroids on sputum bacterial and viral loads in COPD. Eur Respir J 2017; 50: 1700451.

38 Dicker AJ, Crichton ML, Pumphrey EG, et al. Neutrophil extracellular traps are associated with disease severity and microbiota diversity in patients with chronic obstructive pulmonary disease. I Allergy Clin Immunol 2018; 141: 117-127.

39 Ghebre MA, Pang PH, Diver S, et al. Biological exacerbation clusters demonstrate asthma and chronic obstructive pulmonary disease overlap with distinct mediator and microbiome profiles. J Allergy Clin Immunol 2018; 141: 2027-2036.

40 Rogers GB. Inflammation, age and changing microbiology: the search for causation in the cystic fibrosis airways. Eur Respir J 2017; 50: 1701935.

41 Byun MK, Chang J, Kim HJ, et al. Differences of lung microbiome in patients with clinically stable and exacerbated bronchiectasis. PLoS One 2017; 12: e0183553.

42 Rogers GB, van der Gast CJ, Cuthbertson L, et al. Clinical measures of disease in adult non-CF bronchiectasis correlate with airway microbiota composition. Thorax 2013; 68: 731-737.

43 Tunney MM, Einarsson GG, Wei L, et al. Lung microbiota and bacterial abundance in patients with bronchiectasis when clinically stable and during exacerbation. Am J Respir Crit Care Med 2013; 187: 1118-1126.

44 Chalmers JD, Goeminne P, Aliberti S, et al. The bronchiectasis severity index. An international derivation and validation study. Am J Respir Crit Care Med 2014; 189: 576-585.

45 Aksamit TR, O’Donnell AE, Barker A, et al. Adult patients with bronchiectasis: a first look at the US Bronchiectasis Research Registry. Chest 2017; 151: 982-992.

46 Rogers GB, Bruce KD, Martin ML, et al. The effect of long-term macrolide treatment on respiratory microbiota composition in non-cystic fibrosis bronchiectasis: an analysis from the randomised, double-blind, placebo-controlled BLESS trial. Lancet Respir Med 2014; 2: 988-996.

47 Cox MJ, Turek EM, Hennessy C, et al. Longitudinal assessment of sputum microbiome by sequencing of the 16S rRNA gene in non-cystic fibrosis bronchiectasis patients. PLoS One 2017; 12: e0170622.

48 Woo TE, Lim R, Heirali AA, et al. A longitudinal characterization of the non-cystic fibrosis bronchiectasis airway microbiome. Sci Rep 2019; 9: 6871.

49 Woo TE, Duong J, Jervis NM, et al. Virulence adaptations of Pseudomonas aeruginosa isolated from patients with non-cystic fibrosis bronchiectasis. Microbiology 2016; 162: 2126-2135.

50 Taylor SL, Rogers GB, Chen AC-H, et al. Matrix metalloproteinases vary with airway microbiota composition and lung function in non-cystic fibrosis bronchiectasis. Ann Am Thorac Soc 2015; 12: 701-707.

51 Hill AT, Haworth CS, Aliberti S, et al. Pulmonary exacerbation in adults with bronchiectasis: a consensus definition for clinical research. Eur Respir J 2017; 49: 1700051.

52 Sibila O, Laserna E, Shoemark A, et al. Airway bacterial load and inhaled antibiotic response in bronchiectasis. Am J Respir Crit Care Med 2019; 200: 33-41.

53 Serisier DJ, Martin ML, McGuckin MA, et al. Effect of long-term, low-dose erythromycin on pulmonary exacerbations among patients with non-cystic fibrosis bronchiectasis: the BLESS randomized controlled trial. JAMA 2013; 309: 1260-1267.

54 Rogers GB, Zain NMM, Bruce KD, et al. A novel microbiota stratification system predicts future exacerbations in bronchiectasis. Ann Am Thorac Soc 2014; 11: 496-503.

55 Araújo D, Shteinberg M, Aliberti S, et al. The independent contribution of Pseudomonas aeruginosa infection to long-term clinical outcomes in bronchiectasis. Eur Respir J 2018; 51: 1701953

56 Araújo D, Shteinberg M, Aliberti S, et al. Standardised classification of the aetiology of bronchiectasis using an objective algorithm. Eur Respir J 2017; 50: 1701289.

57 Aliberti S, Lonni S, Dore S, et al. Clinical phenotypes in adult patients with bronchiectasis. Eur Respir J 2016; 47: $1113-1122$ 
Vallières E, Tumelty K, Tunney MM, et al. Efficacy of Pseudomonas aeruginosa eradication regimens in bronchiectasis. Eur Respir J 2017; 49: 1600851.

59 Kelly C, Chalmers JD, Crossingham I, et al. Macrolide antibiotics for bronchiectasis. Cochrane Database Syst Rev 2018; 3: CD012406.

60 Mustafa M-H, Khandekar S, Tunney MM, et al. Acquired resistance to macrolides in Pseudomonas aeruginosa from cystic fibrosis patients. Eur Respir J 2017; 49: 1601847.

61 Mac Aogáin M, Tiew PY, Lim AYH, et al. Distinct “immunoallertypes" of disease and high frequencies of sensitization in non-cystic fibrosis bronchiectasis. Am J Respir Crit Care Med 2019; 199: 842-853.

62 Mac Aogáin M, Chandrasekaran R, Lim AYH, et al. Immunological corollary of the pulmonary mycobiome in bronchiectasis: the CAMEB study. Eur Respir J 2018; 52: 1800766.

63 Gao Y-H, Guan W-J, Xu G, et al. The role of viral infection in pulmonary exacerbations of bronchiectasis in adults: a prospective study. Chest 2015; 147: 1635-1643.

64 Bateman ED, Hayashi S, Kuwano K, et al. Latent adenoviral infection in follicular bronchiectasis. Am J Respir Crit Care Med 1995; 151: 170-176.

65 Kapur N, Mackay IM, Sloots TP, et al. Respiratory viruses in exacerbations of non-cystic fibrosis bronchiectasis in children. Arch Dis Child 2014; 99: 749-753.

66 Rytel MW, Conner GH, Welch CC, et al. Infectious agents associated with cylindrical bronchiectasis. Dis Chest 1964; 46: 23-28.

67 Mitchell AB, Mourad B, Buddle L, et al. Viruses in bronchiectasis: a pilot study to explore the presence of community acquired respiratory viruses in stable patients and during acute exacerbations. BMC Pulm Med 2018; 18: 84 .

68 Koh W-J, Moon SM, Kim S-Y, et al. Outcomes of Mycobacterium avium complex lung disease based on clinical phenotype. Eur Respir J 2017; 50: 1602503.

69 Diel R, Jacob J, Lampenius N, et al. Burden of non-tuberculous mycobacterial pulmonary disease in Germany. Eur Respir J 2017; 49: 1602109.

70 van Ingen J, Aksamit T, Andrejak C, et al. Treatment outcome definitions in nontuberculous mycobacterial pulmonary disease: an NTM-NET consensus statement. Eur Respir J 2018; 51: 1800170.

71 Hermon-Taylor J. Mycobacterium avium subspecies paratuberculosis, Crohn's disease and the Doomsday scenario. Gut Pathog 2009; 1: 15.

72 Sulaiman I, Wu BG, Li Y, et al. Evaluation of the airway microbiome in nontuberculous mycobacteria disease. Eur Respir J 2018; 52: 1800810

73 Maughan H, Cunningham KS, Wang PW, et al. Pulmonary bacterial communities in surgically resected noncystic fibrosis bronchiectasis lungs are similar to those in cystic fibrosis. Pulm Med 2012; 2012: 746358.

74 Purcell P, Jary H, Perry A, et al. Polymicrobial airway bacterial communities in adult bronchiectasis patients. BMC Microbiol 2014; 14: 130.

75 Rogers GB, van der Gast CJ, Serisier DJ. Predominant pathogen competition and core microbiota divergence in chronic airway infection. ISME J 2015; 9: 217-225.

76 van der Gast CJ, Cuthbertson L, Rogers GB, et al. Three clinically distinct chronic pediatric airway infections share a common core microbiota. Ann Am Thorac Soc 2014; 11: 1039-1048.

77 Charalampous T, Richardson H, Kay G. Nanopore metagenomics enables rapid clinical diagnosis of bacterial lower respiratory infection. Nat Biotechnol 2019; 37: 783-792.

78 Charalampous T, Richardson H, Kay G, et al. Diagnosis of lower respiratory tract infections using nanopore sequencing. Eur Respir J 2018; 52: Suppl. 62, PA5308.

79 Boutin S, Graeber SY, Stahl M, et al. Chronic but not intermittent infection with Pseudomonas aeruginosa is associated with global changes of the lung microbiome in cystic fibrosis. Eur Respir J 2017; 50: 1701086

80 O'Neill K, Bradley JM, Reid A, et al. Airway infection, systemic inflammation and lung clearance index in children and adults with cystic fibrosis. Eur Respir J 2018; 51: 1701704. 